\title{
Oficinas e jogos de variação linguística
}

Workshops and games on linguistic variation

Monique Débora Alves de Oliveira, mestranda, FAPERJ/UFRJ/SME, mnqdbr@gmail.com.

\section{Resumo}

Este trabalho tem a preocupação de apresentar uma proposta de abordagem de variantes linguísticas de diferentes fenômenos, através de análise contrastiva e de jogos na aula de língua portuguesa.

Palavras Chave: Jogos, ensino, língua portuguesa.

\section{Abstract}

We aim with this work to present a proposal for approaching linguistic variants through contrastive analysis and games in the Portuguese language classes.

Keywords: Games, teaching, Portuguese language. 


\section{Introdução}

Dentre as vertentes da Sociolinguística no Brasil, a faceta educacional, como definida por Bortoni-Ricardo (2014), preocupa-se com a aplicação dos resultados das pesquisas sociolinguísticas na solução de problemas educacionais, no que tange ao ensino de língua portuguesa, através da busca por propostas de trabalho pedagógico, que sejam mais efetivas para tratar a heterogeneidade linguística.

Este trabalho tem a preocupação de apresentar uma proposta de abordagem de variantes linguísticas de diferentes fenômenos, através de análise contrastiva e de jogos na aula de língua portuguesa.

\section{Problema}

O estudo de língua portuguesa no Brasil apresenta, por parte dos professores, desafios de níveis diferentes. Primeiramente, há de se admitir que, apesar do avanço dos estudos da Sociolinguística no Brasil, muitos professores ainda ensinam apenas a norma padrão, como definida por Faraco (2008). Por outro lado, os professores que já reconhecem a variação linguística e a necessidade de trabalhar essa heterogeneidade na sala de aula, encontram dificuldades para executar esta tarefa, em virtude da escassez de materiais específicos para este fim. Além disso, o alunato que frequenta as aulas, geralmente, é heterogêneo em si: há alunos com conhecimentos linguísticos de diferentes normas.

Esses desafios iniciais acabam servindo de motivação para aulas baseadas apenas nos livros didáticos oferecidos pelo MEC. Esse tipo de material tem sido analisado e criticado nos últimos anos, pois, em sua grande maioria, apresenta apenas um capítulo isolado sobre variação linguística, veiculando informações principalmente sobre variação regional ou temporal, conforme atestado por Lima (2014). Isso não colabora para que o professor de língua portuguesa tenha meios de trabalhar a heterogeneidade linguística, uma vez que os manuais didáticos não têm prestado esse serviço. Dessa forma, surge a necessidade de atender ao objetivo da Sociolinguística Educacional, de elaborar propostas pedagógicas mais efetivas, para colaborar com o ensino de língua portuguesa, tanto dos professores já familiarizados com os resultados das pesquisas sociolinguísticas quanto dos que ainda não estão.

Além disso, notamos nas atividades propostas pelos livros didáticos e por professores de ensino fundamental um viés tradicionalista muito forte. Entendemos tradicionalismo como, por exemplo, a postulação de exercícios que, mesmo contextualizados, possuem como objetivo a simples verificação da assimilação de um conteúdo, considerando o aluno um ser passivo não apenas no momento de receber a aprendizagem, mas também no momento de produção dessa verificação. Completar lacunas, encontrar respostas prontas e fazer isso de modo isolado e não interessante para o aluno são situações frequentes. 


\section{Propósito}

O objetivo principal do nosso trabalho foi o desenvolvimento de oficinas que se prestassem a trabalhar conteúdos diversos sobre variação linguística e gramática, em sala de aula, a partir da diagnose do conhecimento inicial da turma sobre os temas abordados e da aplicação de propostas didáticas lúdicas.

Essa diagnose inicial foi realizada através de testes objetivos sobre o tema, realizados pelos alunos para estabelecer a noção inicial e intuitiva que eles tinham sobre o mesmo. Após essa etapa, os alunos foram apresentados ao tema através de aulas expositivas e debates sobre 0 assunto escolhido. Durante esses debates, o professor teve a oportunidade de preencher, com os alunos, as posições em que se encontrariam as variantes em discussão, dentro de continua de variação, como proposto por Bortoni-Ricardo (2004). Finalmente, atividades lúdicas, como jogos diversos, seriam alvo da participação dos alunos, com o objetivo de, através da descontração provocada pelo tipo de atividade escolhida, gerar a reflexão sobre o fenômeno variável em estudo e as noções gramaticais a ele subjacentes.

\section{Abordagens teóricas}

Nossa proposta de oficinas de variação linguística, para o ensino de gramática, tem como base dois trabalhos distintos, que abordam variação linguística através de análise contrastiva, a saber, Wheeler e Swords $(2006,2010)$ e Cyranka (2010).

O trabalho de Wheeler e Swords $(2006,2010)$ constitui nossa primeira base teórica. As autoras propõem que a escola deve operar de modo explícito a alternância de código entre o não-padrão (nonstandard) e o padrão da língua (standard). Nessa proposta, a escola não apenas traz a norma não-padrão para a sala de aula, como a ensina e faz com que os alunos a pratiquem. Isso acontece para que os alunos percebam que a norma que eles dominam (a não-padrão) possui regras e é legítima. Desse modo, pensam as autoras, os alunos terão mais facilidade em perceber que a norma padrão, adotada pela escola, também possui regras e legitimidade, uma vez que deve ser usada em determinados contextos. Apesar de baseados no trabalho de análise contrastiva realizados pelas autoras, cabe ressaltar que não estamos trabalhando com a ideia de duas normas opostas colocadas em extremos de uma linha, mas optamos por abordar a ideia de continua de variação, como posposto por Bortoni-Ricardo (2004).

Nossa segunda base teórica é a pesquisa realizada por Cyranka (2010), cujo objetivo era trabalhar os continua de variação linguística com alunos do Ensino Fundamental e Médio, em Juiz de Fora (MG). Uma pesquisa-ação foi desenvolvida, sob a hipótese de que o tratamento apropriado da variação linguística poderia contribuir para educação linguística dos alunos. Isso seria desenvolvido de modo que eles construíssem crenças sobre seu próprio dialeto, e pudessem elaborar continua de variação linguística, com as variantes apresentadas como pertencentes 
à norma culta urbana e as variantes utilizadas por eles, em diferentes situações de formalidade ou informalidade.

Esses dois trabalhos nos inspiraram pela abordagem que fizeram das variantes linguísticas, através da análise contrastiva das regras gramaticais que motivavam a variação e também pela possibilidade da construção de continua de variação com os alunos, ampliando a educação linguística.

Métodos

A metodologia empregada para a elaboração das atividades das oficinas foi a de análise contrastiva, como utilizada por Cyranka (2010) e por Wheeler e Swords (2006, 2010), em trabalhos semelhantes. Essa metodologia consiste em contrastar variantes linguísticas de um mesmo fenômeno, analisando as regras que condicionam o surgimento de uma ou outra variante.

Esse método de análise contrastiva serviu para que os alunos pudessem comparar regras que determinavam o surgimento de uma variante linguística em um contexto socioeconômico. A partir desse contraste feito por eles, as variantes poderiam ser organizadas dentro dos continua, possibilitando que os alunos se conscientizassem das possibilidades de uso da língua, de acordo com os contextos sociais adequados, nos registros formais ou informais, falados ou escritos.

\section{Considerações}

Nesta breve apresentação do nosso trabalho com oficinas de variação linguística, buscamos levantar os principais pontos que motivaram a elaboração da nossa proposta. Partimos de uma necessidade da Sociolinguística Educacional, que tem se esforçado para prover materiais pedagógicos para o ensino de língua portuguesa, tomando por base os resultados das pesquisas sociolinguísticas já realizadas no decorrer das últimas décadas. Fenômenos de variação nos níveis fonético/fonológicos, que motivam dificuldades na escrita, por exemplo, já foram pesquisados pela Sociolinguística, no âmbito da Teoria da Variação e Mudança. Cabe aos trabalhos inseridos na vertente educacional a elaboração de materiais pedagógicos que possam servir de aporte para o professor, que será responsável por trabalhar esses conteúdos em sala de aula.

Nossa proposta buscou elaborar oficinas para abordar conteúdos de variação linguística e gramática com alunos de $6^{\circ}$ e $7^{\circ}$ anos, em uma escola municipal, no estado do Rio de Janeiro. No entanto, acreditamos que esse tipo de trabalho não deve ficar limitado apenas a esse ambiente, no qual foi desenvolvido. Muito pelo contrário, as oficinas podem ser desenvolvidas em diferentes salas de aula, por professores interessados em desenvolver em seus alunos um conhecimento mais apropriado sobre heterogeneidade linguística e formas representativas dos continua de variação linguística, através da análise contrastiva de regras gramaticais subjacentes à variação. 


\section{Referências Bibliográficas}

BORTONI-RICARDO, S. M. Educação em língua materna: a sociolinguística na sala de aula. São Paulo: Parábola editorial, 2004.

Manual de Sociolinguística. São Paulo: Contexto, 2014.

CYRANKA, L. F. et al. A sociolinguística no ensino fundamental: Resultados de uma pesquisa-ação. Linhas Críticas, Brasília, DF, v. 16, n. 31, p. 361-376, jul./dez. 2010.

FARACO, C. Norma culta brasileira: desatando alguns nós. São Paulo: Parábola editorial, 2008.

LIMA, R. J. Variação linguística e livros didáticos de português: análises, reanálises e perspectivas. In: MARTINS, M. A.; VIEIRA, S. R.; TAVARES, M. A. Ensino de Português e Sociolinguística. São Paulo: Editora Contexto, 2014. p. 115132.

WHEELER, R., SWORDS, R. Code-Switching: Teaching Standard English in urban classrooms. Urbana: IL, National Council of Teachers of English, 2006.

Code-Switching lessons grammar strategies for

linguistically diverse writers. Grade 3- 6. Portsmouth, NH: Heinemann, 2010. 